\title{
Epidermal field carcinogenesis in bald-headed: An attempt at finetuning early non-invasive detection
}

\author{
PASCALE QUATRESOOZ, EMMANUELLE XHAUFLAIRE-UHODA, \\ CLAUDINE PIÉRARD-FRANCHIMONT and GÉRALD E. PIÉRARD \\ Department of Dermatopathology, University Hospital of Liège, BE-4000 Liège, Belgium
}

Received November 17, 2008; Accepted February 4, 2009

DOI: $10.3892 /$ or_00000356

\begin{abstract}
Skin weathering and photoaging of the balding scalp have not attracted much investigative attention so far. However, the concept of field cancerization, in particular actinic field carcinogenesis, is likely applicable to this part of the body. The aim of the study was to finetune the epidermal actinic changes present on hairlessness scalp. The ultraviolet light-enhanced visualization (ULEV) method was used to assess a series of 50 healthy men older than 50 years with documented baldness for over 15 years. They were scrutenized looking for altered epidermal structures corresponding to photoaging-associated changes. Attention was focused on the faint mosaic melanoderma (FMM) and atypical scaliness. Observations were made on the scalp and forehead. FMM was recognized in each case. It presented either as a single manifestation of photoaging or it was associated with an unusual pattern of discrete rimmed scaliness. In this latter case histology and morphometry disclosed keratinocyte dysplasia. A similar scaly pattern was not seen on the forehead. Subtle skin surface changes were disclosed on long-standing sun-exposed balding scalps. The scaly aspect was distinct from dandruff, seborrheic dermatitis or any other common inflammatory scalp dermatosis. The presently described changes had not previously been described during early balding. It is suggested that the presently described condition may be associated with or indicative for actinic field carcinogenesis and incipient keratinocyte dysplasia.
\end{abstract}

\section{Introduction}

Scalp weathering of bald-headed men in part encompasses epidermal changes resulting from chronic actinic damage. The corresponding early clinical signs include faint mosaic melanoderma (FMM) (1), multiple actinic lentigines and some

Correspondence to: Professor G.E. Piérard, Department of Dermatopathology, University Hospital of Liège, CHU Sart Tilman, B-4000 Liège, Belgium

E-mail: gerald.pierard@ulg.ac.be

Key words: stratum corneum, field cancerogenesis, subclinical melanoderma, keratinocyte dysplasia, photoaging skin surface roughening. A little later, actinic keratoses may appear as small warty excrescences or scaly pink patches. They usually develop in clusters, although single lesions may occur occasionally. These keratoses rarely cause much diagnostic difficulty. However, in the early stages, flat brown actinic keratoses may be confused with early seborrheic keratoses, actinic lentigines, lentigo malignant melanoma or desmoplastic melanoma $(2,3)$. In their later stages, a few actinic keratoses may give rise to aggressive squamous cell carcinomas (2-5).

Many skin cells, in particular keratinocytes, are susceptible to damage due to ultraviolet (UV) and near infrared radiation (IRA) (6). Indeed, functional properties of keratinocytes have been reported to be profoundly affected by chronic UV and IRA exposures as early as at age 30 (6-8). Chronic UV exposure impairs homeostasis of keratinocyte proliferation and apoptosis (9). Baldness offers a unique opportunity to investigate these lesions. A study suggested that 35 years or more were required for keratoses to develop after the onset of complete baldness (10). Men of light complexion and blue/ green eyes were more at risk, and the earlier that baldness occurred the greater the risk.

Field cancerization $(11,12)$ occurring in the skin is considered to be the initial step leading to intraepidermal neoplasias (13-16). UV light photography, in particular the UV light-enhanced visualization (ULEV) method (1,17-20), is a convenient means for highlighting early signs of this type of skin weathering.

The aim of the present study was to explore the skin surface changes of photoaging scalp that could represent early signs of actinic field carcinogenesis.

\section{Materials and methods}

The study was conducted in accordance with the Declaration of Helsinki and its subsequent amendments. The patients had given their informed, witnessed and signed consent. A series of 50 healthy men of phototype II-III, presenting with documented baldness for over 15 years were enrolled during winter season. The subjects were aged 51-63 years (median 58.2 years). They were indoor workers and always lived in the region of Liège without being exposed to a sunny climate. They recalled rare sunburns on the scalp. The bald area and the forehead were scrutinized using the previously described ULEV method (17-20).

ULEV assessments were performed using a computerassisted CCD camera equipped with an internal UV-emitting 
Table I. Patterns of subclinical skin mottling.

- Pin point: minute irregularly distributed darker spots

- Follicular dots: speckled perifollicular darker rings

- Small macules: small interfollicular darker areas

- Globular macules: accretive and circinate confluence of smaller macules

- Streaky macules: elongated darker areas along wrinkles

- Confluent macules: massive darker areas

unit (Visioscan ${ }^{\circledR}$ VC98, C+K electronic, Cologne, Germany). The generated digital signals corresponded to 256 gray levels, ranging from zero for black to 256 for white. Each evaluation area consisted of four contiguous Visioscan ${ }^{\circledR}$ fields. The examined sites were clinically featureless without any evidence for melanotic heterogeneity, and without any obvious desquamation. The camera was closely applied to the skin surface. The descriptive patterns of the mosaic hyperpigmentation were assessed as described in Table I. The computerprocessed ULEV image recordings were used to derive the number of $0.1 \mathrm{~mm}^{2}$ spots per $\mathrm{cm}^{2}$ of skin surface with different levels of melanotic intensity. In addition, the relative area $(\%)$ of the darker spots and the median gray levels were averaged for the four fields on each evaluation site.

The medians and ranges of ULEV data were recorded at both evaluation sites. The non-parametric Wilcoxon matched paired test was used to compare the two test sites. A p-value $<0.05$ was considered statistically significant.

In 9 patients who showed an unusual ULEV pattern of discrete scaliness on the scalp, a 2-mm punch biopsy was performed for histological examination and morphometric assessment of epidermal structures. As an internal control for each case, another biopsy was taken from the inner aspect of the arm. The slides were quantitatively assessed using an Analysis Olympus image analyzer. Measurements and interpretation of data were performed as previously described (21). In short, the cross-sectional area of the epidermis was measured. In addition, the length along the junction between stratum granulosum and stratum corneum was recorded. The average epidermal thickness was calculated as the ratio between the cross-section area of the epidermis and the length of the stratum granulosum - stratum corneum junction. The mean keratinocyte nuclear area, the mean nuclear fraction (\%) and the nuclear form factor were recorded from each nuclear profile separately delineated within each epidermal field.

\section{Results}

The scalp and forehead showed various ULEV patterns which differed among volunteers (Figs. 1-6). In all instances the aspect was uneven, particularly in the melanin pigmentation and in the skin surface scaliness. The melanotic pattern showed melanotic peripilar dots (Fig. 1) or larger interfollicular macules (Fig. 2) as well as areas of sharp depigmentation (Fig. 3). These aspects of FMM were commonly unassociated with scaliness or desquamation (Figs. 1-3).

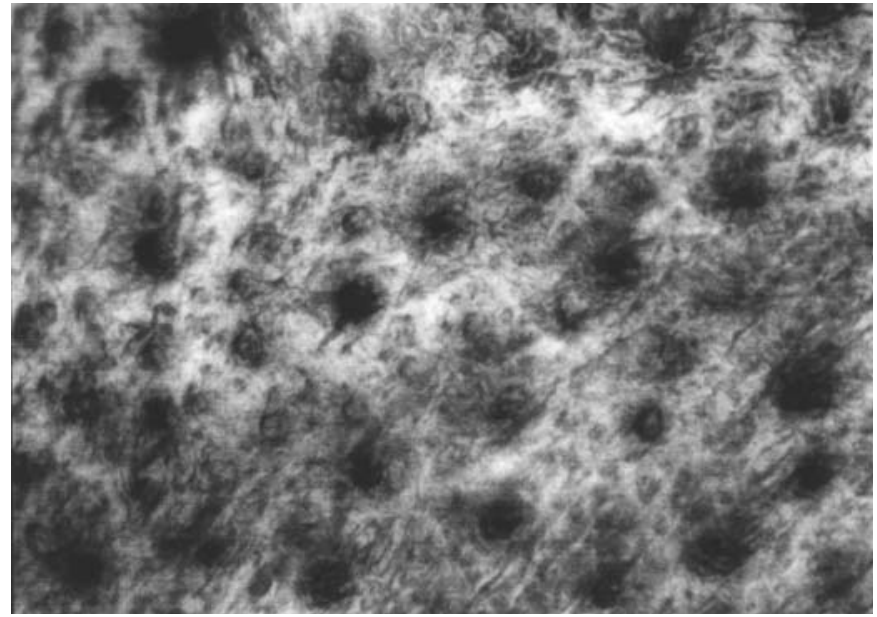

Figure 1. Speckled melanotic peripilar dots.

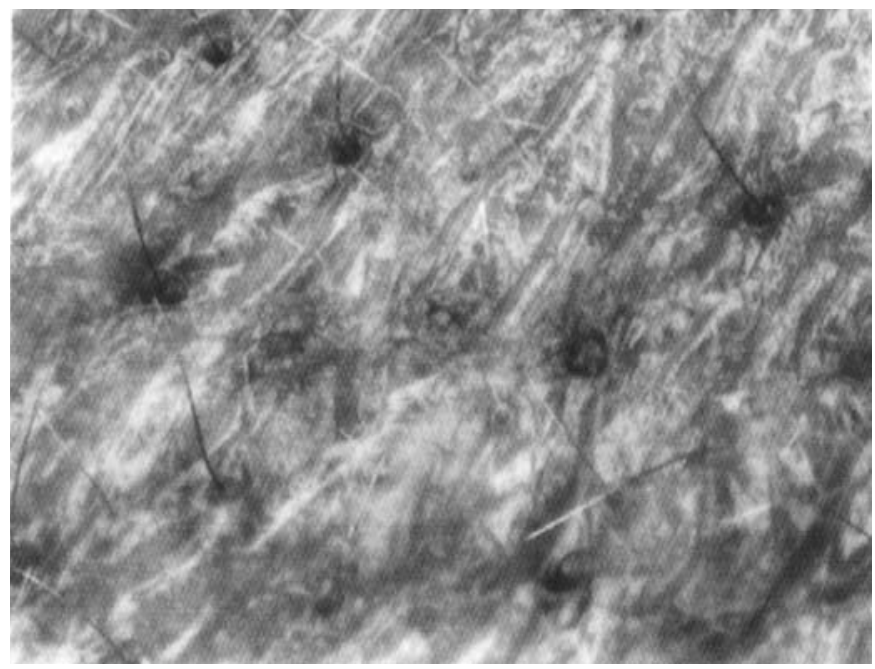

Figure 2. Interfollicular melanotic globules.

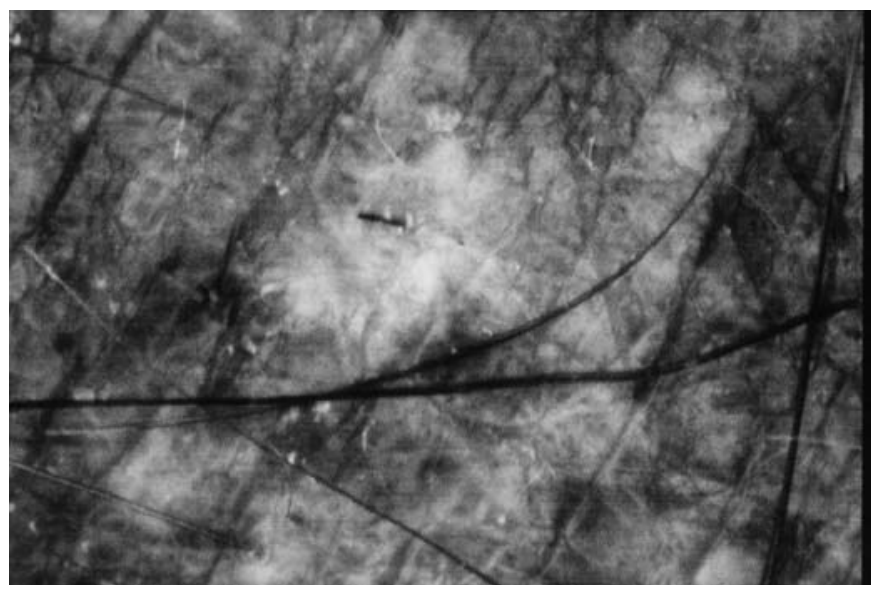

Figure 3. Sharply delimited depigmented macule.

An unusual scaly pattern was, however, recognized in a minority (12/50) of cases, and was often superimposed to FMM (Figs. 4-6). At the ULEV examination, scaliness was discrete and restricted to a thin circinate rim at the periphery 


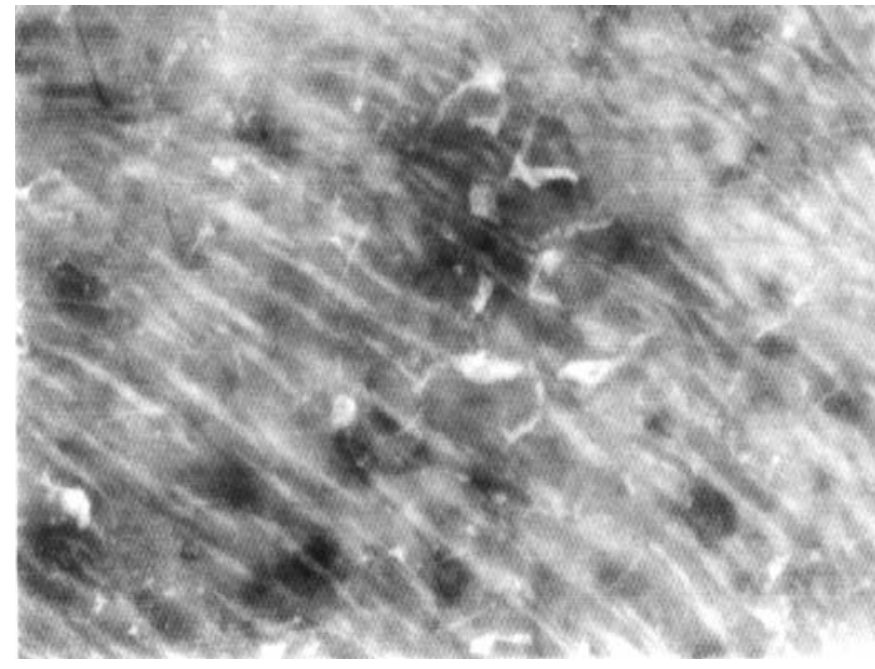

Figure 4. Discrete focal scaling superimposed to faint mosaic melanoderma.

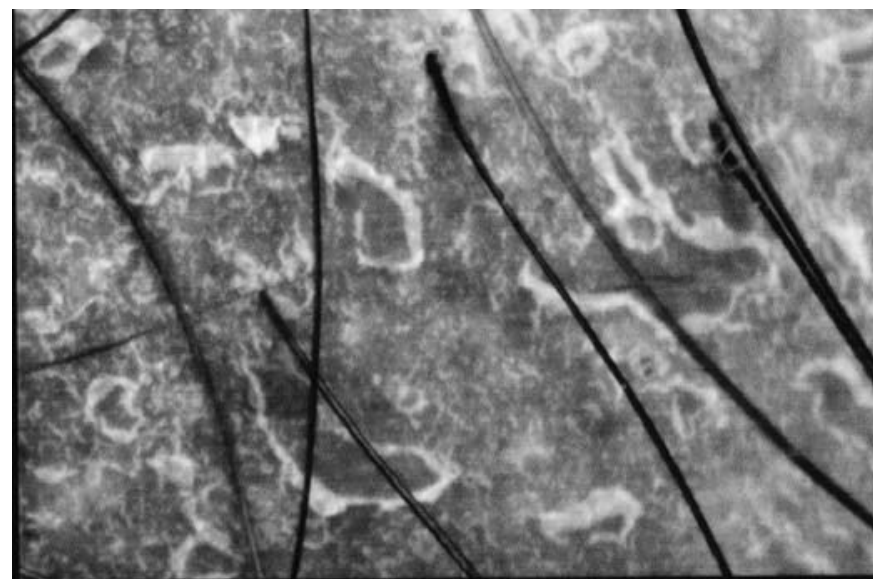

Figure 5. Rims of scaliness delimiting irregularly shaped areas.

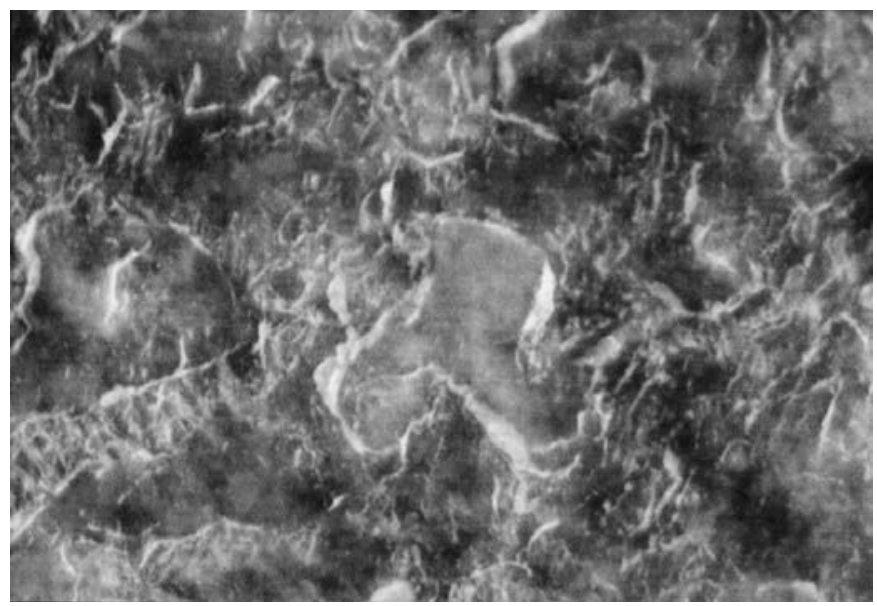

Figure 6. Rims of scaliness at the junction between areas with distinct melanoderma intensity.

of small clear macules. The breadth of these rims was quite uniform (Figs. 4-6) and never associated with adherent or lifted scales of larger size. The histological findings and
Table II. Morphometric assessment of the epidermis.

\begin{tabular}{lll}
\hline Parameter & Scalp & Inner arm \\
\hline Mean epidermal thickness $(\mu \mathrm{m})$ & $51.2 \pm 14.1$ & $44.6 \pm 6.6$ \\
Nuclear area $\left(\mu \mathrm{m}^{2}\right)$ & $33.4 \pm 6.7$ & $28.4 \pm 2.8$ \\
Nuclear form factor & $13.5 \pm 5.2$ & $11.7 \pm 1.9$ \\
Nuclear fraction $(\%)$ & $26.6 \pm 8.2$ & $24.5 \pm 4.2$ \\
\hline
\end{tabular}

morphometric assessments are presented in Table II. The epidermis was significantly thicker $(\mathrm{p}<0.01)$ on the scalp than on the inner arm. Similarly the keratinocyte nuclear area was significantly increased $(\mathrm{p}<0.05)$ on the scalp, it also showed increased variability indicating nuclear atypia and cell dysplasia. By contrast, both the nuclear form factor and the nuclear fraction appeared similar on the 2 biopsied sites.

\section{Discussion}

The ULEV method is a unique tool for assessing the skin surface and the epidermal melanization. The presently described FMM was similar to the aspect of a regular bald scalp showing no evidence for chronic actinic damage $(18,20)$. The typical speckled perifollicular FMM had been previously described (17). The main feature about changes in keratinization of balding scalp was previously ascribed to the presence of keratotic plugs at the site of hair follicles (20). They corresponded to funnel-shaped cornified impactions likely representing reservoirs for microorganisms and diverse compounds such as sebum, and xenobiotics as well. They were unrelated to the extent in FMM (20). It was inferred that the follicular plugs were little or not influenced by chronic UV light exposure. Contrasting with these findings, chronic sun exposure appeared in the present study to be responsible for interfollicular changes in the structure of the stratum corneum rather than being confined to the perifollicular area. These alterations were hardly visible to the naked eye. The pattern of scaliness was distinct from that of dandruff and any inflammatory scaly disorder (22).

Keratinocyte dysplasia seen at the sites of discrete scaliness suggested the process of actinic field carcinogenesis. However, the time-honored term dysplasia conceals controversial concepts (23). For some researchers dysplasia signifies that the tissue in question has entered a phase that is irreversible or otherwise that it will lead to neoplasia (21). This is at variance with other authors who separate dysplasia from intraepithelial neoplasia because the latter usually does progress to invasive cancer in time, whereas dysplasia tends either to regress or to remain stationary, very few cases having a tendency to progress.

The validity of the concept of field cancerization is well established (12). The biological continuum between actinic field carcinogenesis, single or multiple actinic keratoses and squamous cell carcinomas is expressed at the clinical level $(3,12)$. The ULEV method helps identifying subjects at risk of actinic field carcinogenesis (1). The possibility of underevaluating the significance of these common skin conditions 
is thus minimized. Trying to get out dogmatic interpretations, it should therefore be more appropriate to define nuclear and architectural atypias rather than mixing up all observations in a concept of dysplasia. Even then, it is difficult to define what should be evaluated in terms of potential risk of malignancy. The current wave of research into the nature of actinic keratoses has emphasized their unpredictable potential for developing full-blown squamous cell carcinoma. In fact, it is unknown which proportion of actinic keratoses progress to squamous cell carcinomas. It has been stated that the likelihood of a squamous cell carcinoma developing from a given actinic keratoses is around the rate of 0.1 per year (24).

In conclusion, we presently report a unique interfollicular microtopographic aspect of scaliness on chronically sunexposed hairlessness scalp. This aspect was associated with keratinocyte atypia and might represent an early clinical manifestation of actinic field carcinogenesis.

\section{Acknowledgements}

This work was supported by a grant from the 'Fonds d' Investissement de la Recherche Scientifique' of the University Hospital of Liège. No other sources of funding were used to assist in the preparation of this manuscript. The authors have no conflicts of interest that are directly relevant to the content of this work. The authors appreciate the excellent secretarial assistance of Mrs. Ida Leclercq.

\section{References}

1. Quatresooz P, Petit L, Uhoda I, Piérard-Franchimont C and Piérard GE: Mosaic subclinical melanoderma: an Achilles heel for UV-related epidermal carcinogenesis. Int J Oncol 25: 17631767,2004

2. Quatresooz P, Piérard-Franchimont C and Piérard GE: Diagnostic challenge of desmoplastic melanoma. Trends Cancer Res 3: 27-34, 2007.

3. Quatresooz P, Piérard-Franchimont C, Paquet P, Hubert P, Delvenne $\mathrm{P}$ and Piérard GE: Crossroads between actinic keratosis and squamous cell carcinoma and novel pharmacological issues. Eur J Dermatol 18: 6-10, 2008

4. Guenthner ST, Hurwitz RM, Buckel LJ and Gray HR: Cutaneous squamous cell carcinomas consistently show histologic evidence of in situ changes a clinicopathologic correlation. J Am Acad Dermatol 41: 443-448, 1999.

5. Lebwohl M: Actinic keratoses epidemiology and progression to squamous cell carcinoma. Br J Dermatol 149: 31-33, 2003.
6. Schroeder P, Haendeler J and Krutmann J: The role of near infrared radiation in photoaging of the skin. Exp Gerontol 43: 629-632, 2008.

7. Bosset S, Bonnet-Duquennoy M, Barre P, et al: Decreased expression of keratinocytes beta 1 integrins in chronically sunexposed skin in vivo. Br J Dermatol 148: 770-778, 2003.

8. Kwon OS, Yoo HG, Han JH, Lee SR, Chung JH and Eun HC: Photoaging-associated changes in epidermal proliferative cell fractions in vivo. Arch Dermatol Res 300: 47-52, 2008.

9. Webb A, Li A and Kaur P: Location and phenotype of human adult keratinocyte stem cells of the skin. Differentiation 72 : 387-395, 2004.

10. Long CC, Turner RJ and Marks R: Actinic keratoses the bald facts. Arch Dermatol 132: 1132-1133, 1996.

11. Slaughter DP, Southwick HW and Smejkal W: 'Field cancerisation' in oral stratified squamous epithelium clinical implications of multicentric origin. Cancer 6: 963-968, 1953.

12. Dakubo GD, Jakupciak JP, Birch-Machin MA and Parr RL: Clinical implications and utility of field cancerization. Cancer Cell Int 7: 2, 2007.

13. Carlson JA, Scott D, Wharton J and Sell S: Incidental histopathologic pattern possible evidence of 'field cancerisation' surrounding skin tumors. Am J Dermatopathol 23: 494-497, 2001.

14. Braakhuis BJ, Tabor MP, Kummer JA, Leemans CR and Brakenhoff RH: A genetic explanation of Slaughter's concept of field cancerization evidence and clinical implications. Cancer Res 63: 1727-1730, 2003

15. Uhoda I, Quatresooz P, Piérard-Franchimont C and Piérard GE: Nudging epidermal field cancerogenesis by imiquimod. Dermatology 206: 357-360, 2003.

16. Vatve M, Ortonne JP, Birch-Machin MA and Gupta G: Management of field change in actinic keratosis. Br J Dermatol 157: S21-S24, 2007.

17. Petit L, Piérard-Franchimont C, Saint Léger D, Loussouarn G and Piérard GE: Subclinical speckled perifollicular melanosis of the scalp. Eur J Dermatol 12: 565-568, 2002.

18. Petit L, Fougouang L, Uhoda I, Smitz S, Piérard-Franchimont C and Piérard GE: Regional variability in mottled photo-induced melanoderma in the elderly. Exp Gerontol 38: 327-331, 2003

19. Piérard-Franchimont $C$, Paquet $P$, Quatresooz $P$ and Piérard GE: Smoothing the mosaic sublinical melanoderma by calcipotriol. J Eur Acad Dermatol Venereol 21: 657-661, 2007.

20. Xhauflaire-Uhoda E, Piérard-Franchimont C, Piérard GE and Quatresooz P: Hairlessness scalp weathering. A study using skin capacitance imaging and ultraviolet light-enchanced visualisation. Clin Exp Dermatol (In press).

21. Barton SP, Pearse AD and Marks R: Derivation of a dysplasia index for epidermal neoplasia. Dermatology 185: 190-195, 1992.

22. Piérard-Franchimont $\mathrm{C}$, Xhaulfaire-Uhoda $\mathrm{E}$ and Piérard GE: Revisiting dandruff. Int J Cosmet Sci 28: 311-318, 2006.

23. Piérard GE: Dysplasia ongoing controversy highlighted by objective measurements? Dermatology 185: 161-162, 1992.

24. Glogau R: The risk of progression to invasive disease. J Am Acad Dermatol 42: 23-24, 2000. 